\title{
Osteoporosis management in patient with renal function impairment
}

\author{
Manejo da osteoporose no paciente com função renal comprometida
}

Guilherme Alcantara Cunha Lima', Francisco de Paula Paranhos-Neto', Giselly Rosa Modesto Pereira' ${ }^{2}$, Carlos Perez Gomes ${ }^{3}$, Maria Lucia Fleiuss Farias'

1 Division of Endocrinology, Universidade Federal do Rio de Janeiro (UFRJ), Rio de Janeiro, RJ, Brazil 2 Division of Nephrology, Universidade Federal Fluminense (UFF), Rio de Janeiro, RJ, Brazil ${ }^{3}$ Division of Nephrology, UFRJ, Rio de Janeiro, RJ, Brazil
Correspondence to: Guilherme Alcantara Cunha Lima Rua Barão da Lagoa Dourada, 340, ap. 1302

28035-212 - Campos dos

Goytacazes, RJ, Brazil

gaclima@yahoo.com.br

Received on Mar/18/2014 Accepted on May/24/2014

DOI: $10.1590 / 0004-2730000003360$

\begin{abstract}
Aging is associated with decreases in bone quality and in glomerular filtration. Consequently, osteoporosis and chronic kidney disease (CKD) are common comorbid conditions in the elderly, and often coexist. Biochemical abnormalities in the homeostasis of calcium and phosphorus begin early in CKD, leading to an increase in fracture risk and cardiovascular complications since early stages of the disease. The ability of DXA (dual energy X-ray absorptiometry) to diagnose osteoporosis and to predict fractures in this population remains unclear. The management of the disease is also controversial: calcium and vitamin $D$, although recommended, must be prescribed with caution, considering vascular calcification risk and the development of adynamic bone disease. Furthermore, safety and effectiveness of osteoporosis drugs are not established in patients with CKD. Thus, risks and benefits of antiosteoporosis treatment must be considered individually. Arq Bras Endocrinol Metab. 2014;58(5):530-9
\end{abstract}

\section{Keywords}

Bone quality; CKD-MBD; DXA; fractures; osteoporosis

\section{RESUMO}

O envelhecimento associa-se tanto ao declínio da qualidade óssea quanto da filtração glomerular. Consequentemente, osteoporose e doença renal crônica (DRC) são comorbidades frequentes em idosos, e muitas vezes coexistem. Anormalidades bioquímicas na homeostase do cálcio e do fósforo surgem precocemente na DRC, causando aumento do risco de fraturas e de complicações cardiovasculares desde fases precoces da doença. A capacidade da densitometria (DXA) em diagnosticar osteoporose e predizer fraturas nessa população é questionável. 0 manejo da doença é também controverso; cálcio e vitamina $D$ são recomendados com cautela, devido ao risco de calcificações vasculares e de doença óssea adinâmica. Além disso, a segurança e a eficácia dos medicamentos para osteoporose ainda não estão estabelecidas em pacientes com DRC. Assim, riscos e benefícios do tratamento para osteoporose devem ser considerados individualmente nesses pacientes. Arq Bras Endocrinol Metab. 2014;58(5):530-9

Descritores

Qualidade óssea; doença renal crônica; densitometria óssea; fraturas; osteoporose

\section{INTRODUCTION}

I $\mathrm{t}$ is not uncommon in daily practice to detect decreased glomerular filtration in patients with osteoporosis, or else to identify bone fragility in patients in conservative treatment for chronic kidney disease $(\mathrm{CKD})$. The management of these patients is often difficult and many doubts persist.
The diagnosis of CKD is given to any individual with a glomerular filtration rate (GFR) below $60 \mathrm{~mL} /$ $\min / 1.73 \mathrm{~m}^{2}$ or when a GFR $\geq 60 \mathrm{~mL} / \mathrm{min} / 1.73 \mathrm{~m}^{2}$ is associated with at least one marker of kidney damage (albuminuria, abnormal urinary sediment, electrolyte abnormalities secondary to tubular disorders, kidney abnormalities detected by histology or imaging me- 
thods, or renal transplantation) present for at least 3 months (1). It is estimated that $5-10 \%$ of the world population have $\mathrm{CKD}$, due to high prevalence of undertreated chronic diseases, like arterial hypertension and diabetes mellitus, and increased life expectancy of the population (2) (see table 1 for the classification of $\mathrm{CKD})$.

Table 1. CKD Classification by GFR (KDIG0 2012)

\begin{tabular}{lcc}
\hline Categories & GFR (mL/min/1.73 $\left.\mathbf{~ m}^{\mathbf{2}}\right)$ & Conditions \\
\hline G1* $^{*}$ & $\geq 90$ & Normal or high \\
G2* $^{*}$ & $60-89$ & Mildly decreased \\
G3a & $45-59$ & Mildly to moderately decreased \\
G3b & $30-44$ & Moderately to severely decreased \\
G4 & $15-29$ & Severely decreased \\
G5 & $<15$ & Renal failure \\
\hline
\end{tabular}

CKD: chronic kidney disease; GFR: glomerular filtration rate.

* In the absence of evidence of kidney damage, G1 and G2 categories do not meet criteria for CKD; ${ }^{* *}$ In relation to the level of young adults.

The estimated GFR (eGFR) can be obtained in different ways. Classically, Cockcroft and Gault equation $[(140-$ age $) /($ serum creatinine $\times 72)] \times 0.85$ if female $)$ is the most used because it is easy to perform and does not involve logarithmic variables. However, it has low accuracy compared to other methods, especially in patients at extremes of age and those with mild increase in serum creatinine, usually overestimating the GFR. The CKD-EPI equation (Chronic Kidney Disease - Epidemiology Collaboration) has higher accuracy, especially in those patients with GFR $>60 \mathrm{ml} / \mathrm{min} / 1,73 \mathrm{~m}^{2}(3)$, and is currently recommended by the international consensus KDIGO 2012 (Kidney Disease: Improving Global Outcomes): GFR $=141 \times \min (\mathrm{SCr} / \kappa, 1)^{\alpha} \times \max$ $(\mathrm{SCr} / \kappa, 1)^{-1209} \times 0.993^{\text {Age }} \times 1.018$ [if female] x 1.159 [if black], where SCr is serum creatinine $(\mathrm{mg} / \mathrm{dL}), \kappa$ is 0.7 for females and 0.9 for males, $\alpha$ is -0329 for females and -0411 for males, min indicates the minimum of $\mathrm{SCr} / \mathrm{k}$ or $\mathrm{l}$ and max indicates the maximum of $\mathrm{SCr} / \mathrm{k}$ or $1(1,3)$. These and other relatively equations used to estimate GFR are available on the Brazilian site www. sbn.org.br and other electronic medical devices.

Many complications of CKD are initiated at early stages of the disease, among which the disturbances in bone metabolism (1). At any age, these patients have increased risk of fragility fractures (4). Despite the accuracy of DXA in the diagnosis and prediction of fractures in the general population, studies in CKD patients fail to demonstrate its ability in determining bone disease (4-11). In addition, some doubts persist on the most adequate osteoporosis drugs to be employed in patients with renal impairment $(12,13)$. In this review only pre-dialysis population will be considered.

\section{OSTEOPOROSIS, BONE FRAGILITY AND CKD}

Osteoporosis is defined as a disorder associated with decreased bone mass and deterioration of bone microarchitecture, with consequent increased risk of fractures (14). This is an important public health problem, due to its high morbidity and mortality, especially in elderly people. The diagnosis of osteoporosis is based on dual-energy $\mathrm{x}$-ray absorptiometry (DXA scan), when patient's bone mineral density (BMD) is 2.5 SD or more below that of a young-adult reference population, or in the presence of fractures in adulthood (hip, vertebra, distal radius, humerus, ribs) due to trauma equal to or less than a fall from standing height, independent of DXA (15). Data on prevalence of osteoporosis in Brazil are variable: Camargo and cols. (16) identified osteoporosis by DXA in 6.4 to $16.1 \%$ of men and 22.2 to $33.2 \%$ of women living in São Paulo. The BRAZOS study, which evaluated 2,420 men and women aged 40 years and older in different regions of Brazil and from different socio-economic classes, reported low-impact fractures in $15.1 \%$ of women and $12.8 \%$ of men (16).

Cunningham and cols. (18) reported that osteoporosis is more common in patients with renal impairment than in the general population. Klawansky and cols. (5) found that $11 \%$ of men and $24 \%$ of women with osteoporosis had GFR $<35 \mathrm{~mL} / \mathrm{min} / 1.73 \mathrm{~m}^{2}$. Ensrud and cols. (4) observed a 2 -fold increased risk of hip fractures in patients with GFR $<45 \mathrm{~mL} / \mathrm{min} / 1.73 \mathrm{~m}^{2}$.

Several factors favor bone fragility in CKD patients. Alterations in bone histology (osteitis fibrosa, where the main component is the high bone turnover due to hyperparathyroidism; adynamic bone disease and osteomalacia, where the primary disorders are the insufficient bone formation and mineralization) can be observed even in asymptomatic individuals (19). Chronic metabolic acidosis, endocrine disorders (hyperparathyroidism, hypogonadism, decreased IGF-1), sedentary lifestyle, medications (glucocorticoids, anticoagulants, immunosuppressive drugs), malnutrition, myopathy, neuropathy, amyloidosis and immobilization are more common in these patients than in the general population, and contribute to the increased risk of bone fractures and complications $(12,20,21)$. 


\section{CHRONIC KIDNEY DISEASE - MINERAL AND BONE DISORDER (CKD-MBD)}

Changes in bone and mineral metabolism occur early in the course of CKD and progress as kidney function declines. These changes are called Chronic Kidney Disease-Mineral and Bone Disorder (CKD$\mathrm{MBD}$ ), which includes renal osteodystrophy, extraskeletal (vascular) calcification related to abnormalities of bone mineral metabolism and excessive mortality (22). Renal osteodystrophy is the component of CKD-MBD that is identified and quantified through bone histomorphometry and includes osteitis fibrosa (hyperparathyroidism), adynamic bone disease and osteomalacia $(1,19)$. Several factors related to the pathophysiology of CKD-MBD have been described as markers of increased cardiovascular risk and mortality in these patients, such as hyperparathyroidism, increased FGF-23 (Fibroblast Growth Factor-23) and metabolic acidosis $(1,23,24)$. The biochemical CKD-MBD abnormalities are summarized in table 2.

Table 2. Metabolic disturbances associated with CKD

\begin{tabular}{l}
\hline Increased PTH \\
Decreased 25-hydroxyvitamin D \\
Decreased calcitriol \\
Increased FGF-23 \\
Metabolic acidosis \\
Increased bone alkaline phosphatase \\
Hyperphosphatemia (late disorder) \\
Hypocalcemia (late disorder) \\
\hline
\end{tabular}

FGF-23: fibroblast growth factor-23.

The elevation in serum PTH is observed from early stages of CKD and results in increased bone resorption in order to maintain calcium balance. Chronic PTH hypersecretion is related to high turnover bone disease, with increased risk of fractures and bone deformities (25). As shown in figure 1 several factors contribute to hyperparathyroidism: a) The decreased pool of functioning nephrons results in limited capacity for calcitriol production (the active form of vitamin D), due to the smaller amount of $1 \alpha$-hydroxylase, the enzyme responsible for the conversion of 25-hydroxyvitamin D (25OHD) in its active form. CKD patients, even at early stages of the disease, also have a higher prevalence of vitamin D insufficiency/ deficiency than that found in the general population
(26). The decrease in intestinal calcium absorption leads to PTH hypersecretion $(25,27)$. The reduced expression of vitamin $\mathrm{D}$ receptor (VDR) and calcium-sensitive $(\mathrm{CaR})$ receptor, increasing bone resistance to PTH action and estimulating its secretion, is also observed $(22,25)$. b) FGF-23 is a phosphatonin produced by osteoblasts and osteocytes which rises very early in CKD to counterbalance phosphate retention. FGF-23 causes inhibition of $1 \alpha$-hydroxylase, contributing to reduced calcitriol synthesis and to secondary hyperparathyroidism (23). Increased serum phosphate further reduces calcitriol synthesis and can precipitate in vessels and soft tissues with calcium, reducing the ionized calcium fraction (indirectly stimulating the PTH secretion) (25). c) CKD also results in inability to generate new bicarbonate needed to buffer the amount of acid generated by the tissues, resulting in acidosis $(21,24)$. Chronic metabolic acidosis occurs early in the course of CKD and can lead to bone fragility in several ways: increased secretion and resistance to PTH, increased osteoclastic activity, increased renal elimination of calcium, bone mineral dissolution and malnutrition $(21,28)$.

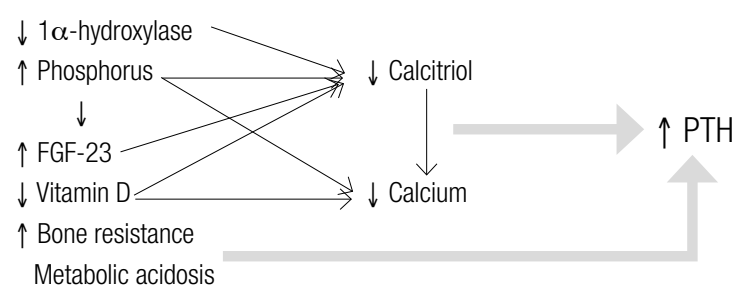

Decreased production of $1 \alpha$-hydroxylase, phosphorus accumulation, increased FGF-23, vitamin $\mathrm{D}$ deficiency, chronic metabolic acidosis and bone resistance to the PTH action results in hyperparathyroidism, increasing bone resorption and predisposing to bone deformities and fractures.

FGF-23: fibroblast growth factor-23.

Figure 1. Pathophysiology of secondary hyperparathyroidism in CKD.

\section{BONE EVALUATION IN CKD}

DXA is the main method used in the diagnosis and treatment of osteoporosis in the general population, as it measures bone mass and determines the risk of fractures (29). However, in patients with CKD, its effectiveness in identifying bone fragility and predicting fractures is uncertain (1). Studies with CKD patients in conservative treatment have shown conflicting results $(4-11,18)$, as summarized in table 3 . Klawansky and cols. (5) observed that osteopenia and osteoporosis were more common in patients with moderate 
(GFR $35-60 \mathrm{~mL} / \mathrm{min} / 1.73 \mathrm{~m}^{2}$ ) or severe $($ GFR $<35$ $\mathrm{mL} / \mathrm{min} / 1.73 \mathrm{~m}^{2}$ ) renal impairment. On the other hand, Hsu and cols. (6) evaluated 13,848 individuals over 20 years with CKD and and did not observe any correlation between BMD and renal function. The role of DXA for predicting fracture risk in pre-dialysis CKD is also undefined (4,8-11), as also shown in table 3. Jassal and cols. (8) reported correlation between GFR and BMD, but not between bone loss by DXA and osteoporotic fractures after a 4-year follow-up, independent of the renal function of participants. Ensrud and cols. (4) observed a negative correlation between femoral neck BMD and risk of hip and spine fractures in women with moderate to severe renal impairment. Nickolas and cols. (30) reported that patients with CKD may present advanced bone disease with a high risk of fractures despite having normal or even high BMD. In a recent study of male patients with grade 3 and $4 \mathrm{CKD}$, we found that only $3.9 \%$ of them had osteoporosis by DXA, but $31.4 \%$ reported low-impact fractures, confirming the ineffectiveness of this method in predicting bone fragility in CKD (11). Due to the inconsistency of the DXA results in CKD patients undergoing conservative treatment, as well as in the dialysis population, the official position of the international consensus KDIGO (1) is that, for patients with stage $3 \mathrm{~b}-5\left(\mathrm{GFR}<45 \mathrm{~mL} / \mathrm{min} / 1.73 \mathrm{~m}^{2}\right)$, DXA should not be used due of its inability to predict fractures and determine the type of renal osteodystrophy, and because it can provide misleading information about the bone health of these patients.

Transiliac bone biopsy with double tetracycline labeling has been the method of choice to define the type and severity of bone disease in CKD-MBD. However, it is an invasive method justified only in specific situations, usually in the more advanced forms of kidney disease (19). Histopathological findings reflecting increased activity of osteoblasts and osteoclasts, and peritrabecular fibrosis indicate osteitis fibrosa, mediated by hyperparathyroidism. Bone mineralization defect with accumulation of non-mineralized osteoid characterizes osteomalacea, and low or very low rate of bone turnover but normal osteoid are indicative of adynamic bone disease. Intermediate degrees may occur $(1,19)$. In the absense of biopsy, serum PTH levels above $400 \mathrm{pg} / \mathrm{mL}$ associated with alkaline phosphatase above 3 times the normal in patients with CKD 5 suggest fibrous osteitis, but do not exclude other disorders, like as adynamic bone disease. In patients with CKD 3 and 4, it is suggested to keep PTH values below the upper normal limit of the assay (1).

High resolution peripheral quantitative computed microtomography (HR-pQCT) is a new and noninvasive method which enables the analysis of bone microarchitecture through peripheral sites: distal radius and distal tibia. It is effective to demonstrate changes in the microstructure during the aging process and also in the detection of the risk of fragility fractures (31). HR-pQCT is able to identify cortical and trabecular bone loss in patients with several degrees of CKD $(32,33)$. ParanhosNeto and cols. recently compared patients with CKD stages 3 and 4 using HR-pQCT, and found a greater impairment of cortical and trabecular bone parameters in stage 4 (lower density and thickness associated with increased trabecular area and cortical perimeter, suggesting trabecularization of cortical bone). FGF-23 and metabolic acidosis were the only independent factors associated with bone alterations, and can be important biomarkers in the clinical management of these patients (34). However, the method does not allow evaluation of bone dynamics or mineralization.

Table 3. Correlation between DXA x kidney function and fractures in CKD predialysis patients

\begin{tabular}{lccl}
\hline Authors & Year & $\begin{array}{c}\text { Number of } \\
\text { participants }\end{array}$ & Results \\
\hline Klawansky and cols. (5) & 2003 & 13,831 & Positive correlation between DXA x kidney function \\
Jassal and cols. (8) & 2007 & 1,713 & Positive correlation between DXA x kidney function, but no correlation between DXA x fractures \\
Hsu and cols. (6) & 2002 & 13,848 & No correlation between DXA x kidney function \\
Jamal and cols. (7) & 2010 & 635 & No correlation between DXA x kidney function \\
Ensrud and cols. (4) & 2007 & 396 & Negative correlation between FN BMD and hip and vertebrae fractures \\
Yenchek and cols. (9) & 2012 & 2,754 & Negative correlation between FN BMD and fragility fractures \\
Jamal and cols. (10) & 2012 & 211 & Negative correlation between FN BMD and hip and vertebral fractures \\
Lima and cols. (11) & 2014 & 51 & Positive correlation between FN BMD x kidney function, but no correlation between DXA and fractures \\
\hline
\end{tabular}

DXA: dual X-ray absorptiometry; BMD: bone mineral density; FN: femoral neck; CKD: chronic kidney disease. 


\section{OSTEOPOROSIS TREATMENT IN CKD PATIENTS}

Due to the high prevalence of osteoporosis and CKD$\mathrm{MBD}$, especially in the elderly population, it is not uncommon the coexistence of these conditions. Although both result in bone fragility and increased risk of fractures, differences in pathophysiology must be considered for their proper management. While the central objective of osteoporosis treatment is to maintain or increase bone mass and reduce fracture risk, the main objective in $\mathrm{CKD}-\mathrm{MBD}$ is to restore mineral balance $(12,13)$. In a patient with osteoporosis and decreased glomerular filtration, factors such as the presence of CKD-MBD, effectiveness of osteoporosis drugs in preventing fractures, cardiovascular risk reduction and safety profile are fundamental for the decision to prescribe or not an osteoporosis medication (13).

\section{CKD-MBD management}

The maintenance of serum calcium, phosphorus and $25 \mathrm{OHD}$ within the normal range are recommendations of international consensus KDIGO (1) for patients with CKD stages 3-5. Measures such as adequacy of phosphorus and protein intake, use of phosphate binders, vitamin D supplementation with pro-active (ergo or cholecalciferol) and/or active (calcitriol) are required (35).

The nutritional therapy in pre-dialysis CKD is aimed to control the protein-energy malnutrition, the electrolyte disturbances and metabolic changes. The protein intake in non-dialysis patients with GFR $<30 \mathrm{~mL} /$ $\min / 1.73 \mathrm{~m}^{2}$ should be $0.8 \mathrm{~g} / \mathrm{kg} /$ day, with $50-60 \%$ of proteins of high biological value. It is important to consider that high protein intake results in accumulation of uremic toxins and acceleration of renal damage; on the other hand, low protein intake increases the risk of malnutrition, metabolic acidosis, loss of muscle mass and bone fragility, and does not slow disease progres$\operatorname{sion}(1)$.

Disorders of calcium and phosphorus are uncommon in patients with GFR $>20 \mathrm{~mL} / \mathrm{min} / 1.73 \mathrm{~m}^{2}$ (27). However, with the worsening of renal function, a calcium x phosphorus product above $55(\mathrm{mg} / \mathrm{dl})^{2}$ increases the risk of vessels and tissues calcification and, as a consequence, the cardiovascular risk of these patients (36). In predialysis phase, usually the optimal levels of phosphorus are achieved by protein restriction $(1,35)$. In patients with hyperphosphatemia refractory to dietary measures, the use of phosphorus binders is indicated. In the absence of hypercalcemia, phosphorus binders containing calcium (carbonate, acetate) can be prescribed, but the calcium x phosphorus product and the risk of ectopic calcification should be evaluated. Calcium supplementation is useful in correcting hypocalcemia, in reducing intestinal phosphorus absorption and minimizing hyperparathyroidism in CKD patients (35). Nevertheless, concerns about the potential increase in extra-skeletal calcification risk of and in calcium $\mathrm{x}$ phosphorus product exist $(35,36)$. Even in the general population, calcium salts supplements have been associated with increased risk of cardiovascular events; oral intake of this element through foods like milk, cheese and yogurt seems more adequate (37). Langsetmo and cols. (38) recently published a study on the effects of calcium intake in mortality of a cohort of 9,033 participants: both dairy products and calcium supplementation were protective in women and neutral in men, but the authors did not assess the subgroup of patients with renal impairment. Due to the risk of extra-skeletal calcifications and the potential myocardial deleterious effect of calcium supplementation, especially in patients with known vascular calcification, total amount of elemental calcium should not exceed 1.5 grams per day and be preferentially administered in the diet $(35,37)$.

Replacement of vitamin D (ergocalciferol or cholecalciferol), aiming to correct hypovitaminosis D and minimize hyperparathyroidism, is indicated as in the general population. In individuals with severe renal impairment, decreased $1 \alpha$-hydroxylase enzyme can reduce the effectiveness of ergo or cholecalciferol replacement, making sometimes necessary the use of calcitriol. This agent is important to re-establish optimal calcium and phosphorus levels and minimize hyperparathyroidism, but should be prescribed with caution because of the risk of hypercalcemia, hyperphosphatemia, vascular calcification and adynamic bone disease $(1,39)$.

In moderate to severe CKD patients on conservative treatment, serum PTH should be maintained in the upper limit of normality. When PTH levels are very high, resulting in high turnover disease (osteitis fibrosa), there is an increased rate of bone resorption and fracture risk. When PTH levels are suppressed, resulting in low turnover disease (adynamic bone disease), there is also an increased risk of fractures 
due to low bone formation (1). Moreover, in CKD patients, an accumulation of $\mathrm{N}$-terminal portion of PTH, especially in dialysis patients, may overestimate its serum level (40). The PTH therapeutic target in pre-dialysis patients is not known. KDIGO consensus suggests that in patients with GFR $<45 \mathrm{~mL} /$ $\min / 1,73 \mathrm{~m}^{2}$ and PTH above the normal value, efforts to adequacy of serum phosphorus, calcium and $25 \mathrm{OHD}$ are priority to the absolute values of $\mathrm{PTH}$. Attempts to normalize serum ionized calcium/calcium corrected for albumin, phosphorus, 25OHD and alkaline phosphatase (marker of bone turnover) are more important than the absolute values of PTH, even if they are above normal limits (1). The calcimimetic agent cinacalcet, which reduces the PTH and calcium levels by changing the set point of the calcium-sensitive receptor, is not approved for use in predialysis patients (35). It is worth noting that increased PTH alone is not a good predictor of bone turnover in CKD $(1,35)$. Bone biopsy, although expensive and not widely available, should be considered in doubtful cases to guide treatment (1).

Chronic metabolic acidosis is associated with declining renal function (23) hyperparathyroidism and decreased BMD (28). Raphael and cols. (41) have shown that the maintenance of serum bicarbonate at high-normal levels reduced CKD progression and increased patient survival. Reduction of protein catabolism and the hospitalization rate were also reported $(24,42,43)$. KDIGO consensus (1) establishes that patients with CKD and serum bicarbonate $<22$ $\mathrm{mmol} / \mathrm{L}$ require oral bicarbonate replacement.

\section{Osteoporosis drugs}

Most large-scale studies to determine the effectiveness and safety of osteoporosis drugs in the general population did not include patients with severe renal impairment $\left(\mathrm{GFR}<30 \mathrm{ml} / \mathrm{min} / 1.73 \mathrm{~m}^{2}\right)(12)$. The consensus KDIGO (1) reports safety and efficacy of these drugs in patients with CKD 1-3 without evidence of CKD-MBD, but does not guarantee their use in patients with GFR $<30 \mathrm{~mL} / \mathrm{min} / 1.73 \mathrm{~m}^{2}$, or those with metabolic disturbances of CKD-MBD, recommending bone biopsy with double tetracycline labeling to assess the potential benefit of the prescription in this population. Table 4 summarizes the recommendations for pharmacological classes of osteoporosis drugs.

\section{Bisphosphonates}

These antiresorptive agents, widely used in the treatment of osteoporosis, have been evaluated in patients with low GFR (44). Jamal and cols. (45) evaluated the FIT study subgroup with renal impairment classi-

Table 4. Summary of osteoporosis drugs in CKD

\begin{tabular}{ll}
\hline Classes & \multicolumn{1}{c}{ Comments } \\
\hline Bisphosphonates & Zoledronic acid: not recommended if GFR $<35 \mathrm{~mL} / \mathrm{min} / 1.73 \mathrm{~m}^{2}$ \\
& Oral bisphosphonates: not recommended if GFR $<30 \mathrm{~mL} / \mathrm{min} / 1.73 \mathrm{~m}^{2}$ \\
& Potential benefit in reducing vascular calcification and cardiovascular risk \\
& Potential risk of nephrotoxicity, hypocalcemia and adynamic bone disease \\
Denosumab & Absence of renal elimination \\
& Potential risk of hypocalcemia and adynamic bone disease \\
Strontium ranelate & Safety profile in CKD undefined \\
& Potential increased cardiovascular risk \\
Teriparatide & Safety profile in CKD undefined \\
SERMs & Safe in patients with GFR $>30 \mathrm{~mL} / \mathrm{min} / 1.73 \mathrm{~m} \mathrm{~m}^{2}$ without biochemical abnormalities \\
& Potential benefit in patients with adynamic bone disease \\
& Safe in patients with GFR $>30 \mathrm{~mL} / \mathrm{min} / 1.73 \mathrm{~m}^{2}$ without biochemical abnormalities \\
Calcitonin & Pneffective in prevention of non-vertebral fractures \\
& Potential risk of stroke and thromboembolic events \\
& No studies in patients with CKD-MBD \\
Ineffective in prevention of non-vertebral fractures \\
No lasting effect
\end{tabular}

GFR: glomerular filtration rate; CKD: chronic kidney disease; SERMs: selective estrogen receptor modulators; CKD-MBD: chronic kidney disease - mineral and bone disorder. In patients with GFR $<45 \mathrm{~mL} / \mathrm{min} / 1,73 \mathrm{~m}^{2}$, prior correction of biochemical abnormalities is indicated. Bone biopsy is recommended before prescribing osteoporosis drugs in patients with GFR $<$ $45 \mathrm{~mL} / \mathrm{min} / 1,73 \mathrm{~m}^{2}$, to evaluate CKD-MBD presence. 
fied as CKD 2-4. Treatment with alendronate increased BMD regardless of eGFR, and also reduced the risk of fractures to a similar degree in those with and without reduced renal function. The authors did not report differences in adverse events by renal function. Miller and cols. (46) reviewed 9 studies with risedronate. The analysis included 4,500 patients on placebo and 4,496 patients on risedronate $5 \mathrm{mg} /$ day for up to 3 years. Patients were categorized as having mild (GFR 50 to $<80$ $\mathrm{mL} / \mathrm{min} / 1.73 \mathrm{~m}^{2}$ ), moderate (GFR 30 to $<50 \mathrm{~mL} /$ $\left.\mathrm{min} / 1.73 \mathrm{~m}^{2}\right)$, or severe $\left(\mathrm{GFR}<30 \mathrm{~mL} / \mathrm{min} / 1.73 \mathrm{~m}^{2}\right)$ renal impairment. In both the placebo and risedronate treatment groups, patients with the most severe renal impairment were older and had more severe osteoporosis. Risedronate effectively preserved BMD and reduced the incidence of vertebral fractures. Also, the incidences of overall adverse events and of renal function-related adverse events were similar in both groups. Boonen and cols. (47) evaluated patients with GFR $<35 \mathrm{~mL} / \mathrm{min} / 1.73 \mathrm{~m}^{2}$ receiving zoledronic acid and did not describe worsening of renal function. It is noteworthy that all patients included in these studies had no evidence of CKD-MBD. In contrast, nephrotoxicity in patients receiving pamidronate or ibandronate were reported in a review (48). Miller and cols. (49) have recently published a review of the literature on the renal safety of bisphosphonate use for osteoporosis. The authors concluded that the benefits outweigh risks; and even in elderly, frail, osteoporotic patients with renal impairment, intravenous bisphosphonate therapy administration in accordance with the prescribing information did not result in long-term renal function decline.

The potential benefit of these drugs in reducing the vascular calcification and atherosclerosis progression is still undetermined $(12,44)$. Santos and cols., in a systematic review, analyzed the results of 169 articles that assessed the thickening of the intimamedia of the carotid arteries or the calcification of the aorta and coronary arteries, and suggested that bisphosphonates exert an inhibitory effect on the atherosclerotic process (50).

One concern with bisphosphonate use in CKD patients is the induction of adynamic bone disease, due to the suppression of bone formation, resulting in bone fragility and fractures. Amerling and cols. (51) studied 13 patients with CKD 2-4 in use of bisphosphonates through bone biopsy, and found that all of them developed adynamic bone disease. Thus, bisphosphonates are not indicated in patients with evidence of adynamic bone disease or osteomalacia (31). Hypocalcemia was also reported in patients with evidence of CKD-MBD receiving bisphosphonates, especially after intravenous application of zoledronic acid (12).

\section{Denosumab}

The anti-RANKL monoclonal antibody Denosumab (Dmab) decreases bone resorption and is useful for osteoporosis treatment and prevention of fractures in the general population. One advantage of this product compared to other osteoporosis drugs is that it does not have renal elimination (52). Jamal and cols. (53) evaluated the effects of Dmab on fracture and BMD by level of kidney function in postmenopausal women included in FREEDOM study: the eGFR was $15-29 \mathrm{~mL} / \mathrm{min}$ in $73 ; 30-59 \mathrm{~mL} / \mathrm{min}$ in 2,817 ; $60-89 \mathrm{~mL} / \mathrm{min}$ in 4,069 , and $90 \mathrm{~mL} / \mathrm{min}$ or greater in 842 . None had stage $5 \mathrm{CKD}$. Changes in creatinine and calcium and the incidence of adverse events were similar between groups and did not differ by level of kidney function. Fracture risk reduction and changes in BMD at all sites were in favor of DMAb. Block and cols. (54) studied patients with GFR ranging from > $80 \mathrm{~mL} / \mathrm{min} / 1.73 \mathrm{~m}^{2}$ to kidney failure requiring hemodialysis, after a single-dose of D-mab. In only one patient there was an important reduction in GFR (from baseline values of 14 to $6 \mathrm{~mL} / \mathrm{min} / 1.73 \mathrm{~m}^{2}$ ). The authors found no differences in pharmacokinetics and pharmacodynamics that justified dose adjustment based on GFR. However, as bisphosphonates, Dmab inhibits bone resorption which may provoke hypocalcemia, and limits bone formation, raising concerns about adynamic bone disease (12). More studies are needed to define the risk-benefit ratio of this drug in predialysis $\mathrm{CKD}$.

\section{Strontium ranelate}

This medication rebalances bone remodeling, without a great inhibition of bone resorption, which could reduce the risk of hypocalcemia and adynamic bone disease. However, due to the renal excretion of strontium, it is contra-indicated in patients with a GFR below $30 \mathrm{~mL} / \mathrm{min}$ (CKD grades 4 and 5 ). Recently the EMA (European Medicines Agency), based on reports of patients with cardiovascular complications using this drug, recommended that strontium ranelate should be not be used in patients with 
severe arterial hypertension, previous cardiovascular or cerebrovascular disease (55). As CKD patients are at high risk of cardiovascular complications, more studies are necessary to evaluate risks and benefits of strontium ranelate in patients with moderate CKD (grade 3).

\section{Teriparatide}

This anabolic agent, analogue of PTH, is used to treat osteoporosis, especially in patients with severe disease and multiple fractures (56). In patients with mild to moderate CKD (GFR $30-79 \mathrm{~mL} / \mathrm{min} / 1.73 \mathrm{~m}^{2}$ ) who had normal serum PTH, teriparatide was effective in increasing BMD and reducing the risk of fractures, and also safe (57). As increased PTH levels constitutes a contraindication to teriparatide (56), the use of this drug in $\mathrm{CKD}$, a condition related to hyperparathyroidism, seems inappropriate. Teriparatide might be useful in CKD patients with adynamic bone disease, where hyperparathyroidism is not the central disorder, and in those who underwent prior parathyroidectomy, but few studies have evaluated its use in these conditions (12-13).

\section{Selective estrogen receptor modulators (SERM)}

Raloxifene was evaluated by Ishani and cols. (58) in patients with mild to moderate $\mathrm{CKD}$. It increased BMD and reduced the risk of vertebral fractures. There were no significant side effects, although an increase in raloxifene plasma levels in CKD patients has been published (59). One concern is the increased risk of stroke (60) and fatal deep vein thrombosis, which limits its use in patients with increased risk of thromboembolic and cardiovascular diseases as seen in CKD. Bazedoxifene, another SERM approved for osteoporosis treatment, has also been evaluated in patients with mild to moderate renal impairment. It reduced the risk of fractures and was safe, but the majority of patients included had a GFR $60-90 \mathrm{~mL} /$ $\mathrm{min} / 1.73 \mathrm{~m}^{2}(61)$.

\section{Calcitonin}

The calcium sparing effect of calcitonin in renal tubules might decrease PTH in CKD, a condition associated with hyperparathyroidism. However, tachyphylaxis with prolonged use and lack of efficacy in non-vertebral fractures (62), as well as the paucity of data in $\mathrm{CKD}$ patients do not favor its use in CKD. Calcitonin seems to have an analgesic effect after new vertebral fractures (63), but in clinical practice other methods to relief pain are recommended.

\section{CONCLUSIONS}

CKD patients are at high risk of fractures and bone complications. Several factors are related, and may be present since early stages of the disease when the patient is asymptomatic. The correction of biochemical abnormalities is an important tool to reduce bone complications, regardless of DXA results, as this exam may not reflect the real risk of fractures in this population. Proper nutritional guidance and measures to prevent falls are also fundamental tools.

Osteoporosis drugs can be used in patients with GFR $>45 \mathrm{~mL} / \mathrm{min} / 1.73 \mathrm{~m}^{2}$ as in the general population, but few large-scale studies evaluated their efficacy and safety in patients with more severe degrees of CKD. The absence of consistent results on fracture risk or cardiovascular complications (vascular calcification), the potential risk of adynamic bone disease secondary to decreased bone formation and the lack of widely available method for evaluating the efficacy of the long run treatment make their indication restricted.

In patients with GFR $<45 \mathrm{~mL} / \mathrm{min} / 1.73 \mathrm{~m}^{2}$ and biochemical abnormalities of CKD-MBD, such as secondary hyperparathyroidism, hyperphosphatemia, hypovitaminosis D or chronic metabolic acidosis, we should first correct these disorders. In case of persistent low BMD and/or low impact fractures, a bone biopsy is recommended for evaluating the type of bone disease before starting an osteoporosis medication.

A multidisciplinary team (nephrology, endocrinology, cardiology, nutrition and physiotherapy) acting since the early stages of CKD, and an individualized approach to minimize the influence of the various factors involved in CKD-MBD, are key factors to reduce bone metabolic and cardiovascular risk in these patients.

Disclosure: no potential conflict of interest relevant to this article was reported.

\section{REFERENCES}

1. Kidney disease: improving global outcomes (KDIGO) CKD work group. KDIGO 2012 Clinical Practice Guideline for the Evalu- 
ation and Management of Chronic Kidney Disease. Kidney Int. 2013;3(Suppl):S1-S150.

2. Eknoyan G, Lameire N, Barsoun R, Eckardt K-U, Levin A, Levin N, et al. The burden of kidney disease: improving global outcomes (KDIGO). Kidney Int. 2004;66:1310-4.

3. Levey AS, Stevens LA, Schmid CH, Zhang YL, Castro AF 3rd, Feldman HI, et al.; CKD-EPI (Chronic Kidney Disease Epidemiology Collaboration). A new equation to estimate glomerular filtration rate. Ann Intern Med. 2009;150:603-12.

4. Ensrud KE, Lui $L Y$, Taylor BC, Ishani A, Shlipak MG, Stone KL, et al. Renal function and risk of hip and vertebral fractures in older women. Arch Inter Med. 2007;167:133-9.

5. Klawansky S, Komaroff E, Cavanaugh PF Jr, Mitchell DY, Gordon $\mathrm{MJ}$, Connelly JE, et al. Relationship between age, renal function and bone mineral density in the US population. Osteoporos Int. 2003;14:570-6.

6. Hsu CY, Cummings SR, McCulloch CE, Chertow GM. Bone mineral density is not diminished by mild to moderate chronic renal insufficiency. Kidney Int. 2002;61:1814-20.

7. Jamal SA, Swan VJ, Brown JP, Hanley DA, Prior JC, Papaioannou A, et al.; Canadian Multicentre Osteoporosis Study Research Group. Kidney function and rate of bone loss at the hip and spine: the Canadian Multicentre Osteoporosis Study. Am J Kidney Dis. 2010;55:291-9.

8. Jassal SK, von Muhlen D, Barret-Connor. Measures of renal function, BMD, bone loss, and osteoporotic fracture in older adults: the Rancho Bernardo study. J Bone Miner Res. 2007;22:203-10.

9. Yenchek RH, Ix JH, Shlipak MG, Bauer DC, Rianon NJ, Kritchevsky $\mathrm{SB}$, et al.; Health, Aging, and Body Composition Study. Bone mineral density and fracture risk in older individuals with CKD. Clin J Am Soc Nephrol. 2012;7:1130-6.

10. Jamal SA, Cheung AM, West SL, Lok CE. Bone mineral density by DXA and HR-pQCT can discriminate fracture status in men and women with stages 3 to 5 chronic kidney disease. Osteoporos Int. 2012;23:2805-13.

11. Lima GA, Paranhos-Neto FD, Silva LC, de Mendonça LM, Delgado $A G$, Leite $M \mathrm{Jr}$, et al. Bone density is directly associated with glomerular filtration and metabolic acidosis but do not predict fragility fractures in men with moderate chronic kidney disease. J Clin Densitom. 2014 Apr 4. pii: S1094-6950(14)00031-6.

12. Ott SM. Therapy for patients with CKD and low mineral density. Nat Rev Nephrol. 2013;9:681-92.

13. Gordon PL, Frassetto LA. Management of osteoporosis in CKD stages 3 to 5. Am J Kidney Dis. 2010;55:941-56.

14. Rachner TD, Khosla S, Hofbauer LC. Osteoporosis: now and the future. Lancet. 2011;377:1276-87.

15. Kanis JA, Glüer CC. An update on the diagnosis and assessment of osteoporosis with densitometry. Osteoporos Int. 2000;11:192202.

16. Camargo MB, Cendoroglo MS, Ramos LR, de Oliveira Latorre Mdo R, Saraiva GL, Lage A, et al. Bone mineral density and osteoporosis among a predominantly Caucasian elderly population in the city of São Paulo, Brazil. Osteoporos Int. 2005;16:1451-60.

17. Pinheiro MM, Ciconelli RM, Martini LA, Ferraz MB. Clinical risk factors for osteoporotic fractures in Brazilian women and men: The BRAZilian Osteoporosis Study (BRAZOS). Osteoporos Int. 2009;20:399-408.

18. Cunningham J, Sprague SM, Cannata-Andia J, Coco M, CohenSolal M, Fitzpatrick L, et al. Osteoporosis in chronic kidney disease. Am J Kidney Dis. 2004;43:566-71.

19. Malluche HH, Mawad HW, Faugere MCM. Renal osteodystrophy in the first decade of the new millennium: analysis of 630 bone biopsies in black and white patients. J Bone Miner Res. 2011;26:1368-76.
20. Jamal SA, West SL, Miler PD. Fracture risk assessment in patients with chronic kidney disease. Osteoporos Int. 2012;23:1191-8.

21. Kraut JA, Madias NE. Metabolic acidosis: pathophysiology, diagnosis and management. Nat Rev Nephrol. 2010;6:274-85.

22. Moe S, DrüekeT, Cunningham J, Goodman W, Martin K, Olgaard K, et al.; Kidney Disease: Improving Global Outcomes (KDIGO). Definition, evaluation, and classification of renal osteodystrophy: a position statement from Kidney Disease: Improving Global Outcomes (KDIGO). Kidney Int. 2006;69:1945-53.

23. Ford ML, Smith ER, Tomlinson LA, Chatterjee PK, Rajkumar C, Holt SG. FGF-23 and osteoprotegerin are independently associated with myocardial damage in chronic kidney disease stages 3 and 4. Another link between chronic kidney disease-mineral bone disorder and the heart. Nephrol Dial Transplant. 2012;27:727-33.

24. Kovesdy $\mathrm{CY}$, Anderson JE, Kalantar-Zadeh K. Association of serum bicarbonate levels with mortality in patients with non-dialysis-dependent CKD. Nephrol Dial Transplant. 2009;24:1232-7.

25. Martin KJ, González EA. Metabolic bone disease in chronic kidney disease. J Am Soc Nephrol. 2007;18:875-85.

26. González EA, Sachdeva A, Oliver DA, Martin KJ. Vitamin D insufficiency and deficiency in chronic renal disease. A single center observational study. Am J Nephrol. 2004;24:503-10.

27. Levin A, Bakris GL, Molitch M, Smulders M, Tian J, Williams LA, et al. Prevalence of abnormal serum vitamin D, PTH, calcium, and phosphorus in patients with chronic kidney disease: results of the study to evaluate early kidney disease. Kidney Int. 2007;71:31-8.

28. Lemman J, Bushinski DA, Hamm LL. Bone buffering of acid and base in humans. Am J Physiol. 2003;285:F811-32.

29. Lewiecki EM, Binkley N, Bilezikian JP, Kendler DL, Leib ES, Petak SM. Official positions of the International Society for Clinical Densitometry. Osteoporos Int. 2006;17:1700.

30. Nickolas TL, Leonard MB, Shane E. Chronic kidney disease and bone fracture: a growing concern. Kidney Int. 2008;74:721-31.

31. Dalzell N, Kaptoge S, Morris N, Berthier A, Koller B, Braak L, et al. Bone micro-architecture and determinants of strength in the radius and tibia: age-related changes in a population-based study of normal adults measured with high-resolution pQCT. Osteoporos Int. 2009;20:1683-94.

32. Bacchetta J, Boutroy S, Vilayphiou N, Juillard L, Guebre-Egziabher F, Rognant $\mathrm{N}$, et al. Early impairment of trabecular microarchitecture assessed with HR-pOCT in patients with stage II-IV chronic kidney disease. J Bone Miner Res. 2010;25:849-57.

33. NickolasTL, Stein EM, Dworakowski E, Nishiyama KK, KomandahKosseh M, Zhang CA, et al. Rapid cortical bone loss in patients with chronic kidney disease. J Bone Miner Res. 2013,28:1811-20.

34. Paranhos-Neto FP, Lima GAC, Silva LC, et al. Cortical and trabecular microarchitecture impairment correlates with fibroblast growth factor-23 and metabolic acidosis in men with stages 3 and 4 of chronic kidney disease. ASBMR 2013. Oral poster LB-SA16.

35. Martin KJ, González EA. Long-term management of CKD-mineral and bone disorder. Am J Kidney Dis. 2012;60:308-15.

36. Block GA, Hulbert-Shearon TE, Levin NW, Port FK. Association of serum phosphorus and calcium $\mathrm{x}$ phosphate product with mortality risk in chronic hemodialysis patients: a national study. Am J Kidney Dis. 1998;31:607-17.

37. Reid IR, Bolland MJ, Avenell A, Grey A. Cardiovascular effects of calcium supplementation. Osteoporos Int. 2011;22(6):1649-58.

38. Langsetmo L, Berger C, Kreiger N, Kovacs CS, Hanley DA, Jamal SA, et al. Calcium and vitamin D intake and mortality: results from the Canadian Multicentre Osteoporosis Study (CaMos). J Clin Endocrinol Metab. 2013;98:3010-8.

39. Shoben AB, Rudser KD, de Boer IH, Young B, Kestenbaum B. Association of oral calcitriol with improved survival in nondialyzed CKD. J Am Soc Nephrol. 2008;19:1613-9. 
40. Souberbielle JC, Boutten A, Carlier MC, Chevenne D, Coumaros G, Lawson-Body E, et al. Inter-method variability in PTH measurement: implication for the care of CKD. Kidney Int. 2006;70:345-50.

41. Raphael KL, Wei G, Baird BC, Greene T, Beddhu S. Higher serum bicarbonate levels within the normal range are associated with better survival and renal outcomes in African Americans. Kidney Int. 2011;79:356-62.

42. Ceglia L, Harris SS, Abrams SA, Rasmussen HM, Dallal GE, Dawson-Hughes $B$. Potassium bicarbonate attenuates the urinary nitrogen excretion that accompanies an increase in dietary protein and may promote calcium absorption. J Clin Endocrinol Metab. 2009;94:645-53.

43. Kanda E, Ai M, Yoshida M, Kuriyama R, Shiigai T. High serum bicarbonate level within the normal range prevents the progression of chronic kidney disease in elderly chronic kidney disease patients. BMC Nephrol. 2013;14:4.

44. Toussaint ND, Elder GJ, Kerr PG. Bisphosphonates in chronic kidney disease; balancing potential benefits and adverse effects on bone and soft tissue. Clin J Am Soc Nephrol. 2009;4:221-33.

45. Jamal SA, Bauer DC, Ensrud KE, Cauley JA, Hochberg M, Ishani $A$, et al. Alendronate treatment in women with normal to severely impaired renal function: an analysis of the fracture intervention trial. J Bone Miner Res. 2007;22:503-8.

46. Miller PD, Roux C, Boonen S, Barton I, Dunlop L, Burgio D. Safety and efficacy of risedronate in patients with age-related reduced renal function as estimated by the Cockcroft and Gault method: a pooled analysis of nine clinical trials. $\mathrm{J}$ Bone Miner Res. 2005;20:2105-15.

47. Boonen S, Sellmeyer DE, Lippuner K, Orlov-Morozov A, Abrams $\mathrm{K}$, Mesenbrink $\mathrm{P}$, et al. Renal safety of annual zoledronic acid infusions in osteoporotic postmenopausal women. Kidney Int. 2008;74:641-8.

48. Perazella MA, Markowitz GS. Bisphosphonate nephrotoxicity. Kidney Int. 2008;74:1385-93.

49. Miller PD, Jamal SA, Evenepoel P, Eastell R, Boonen S. Renal safety in patients treated with bisphosphonates for osteoporosis: a review. J Bone Miner Res. 2013;28:2049-59.

50. Santos LL, Cavalcanti TB, Bandeira FA. Vascular effects of bisphosphonates - A sistematic review. Clin Med Insights Endocrinol Diabetes. 2012;5:47-54.

51. Amerling R, Harbord NB, Pullman J, Feinfeld DA. Bisphosphonate use in chronic kidney disease: association with adynamic bone disease in a bone histology series. Blood Purif. 2010;29:293-9.
52. Bone HG, Bolognese MA, Yuen CK, Kendler DL, Miller PD, Yang $\mathrm{YC}$, et al. Effects of denosumab treatment and discontinuation on bone mineral density and bone turnover markers in postmenopausal women with low bone mass. J Clin Endocrinol Metab. 2011;96:972-80.

53. Jamal SA, Ljunggren O, Stehman-Breen C, Cummings SR, McClung MR, Goemaere S, et al. Effects of denosumab on fracture and bone mineral density by level of kidney function. $J$ Bone Miner Res. 2011;26(8):1829-35.

54. Block GA, Bone HG, FangL, Lee E, Padhi D. A single-dose study of denosumab in patients with various degrees of renal impairment. J Bone Miner Res. 2012;27:1471-9.

55. European Medicines Agency recommends that Protelos/Osseor remain available but with further restrictions. EMA/84749/2014. Published on line 21 February 2014.

56. Lindsay R, Scheele WH, Neer R, Pohl G, Adami S, Mautalen C, et al. Sustained vertebral fracture risk reduction after withdrawal of teriparatide in postmenopausal women with osteoporosis. Arch Intern Med. 2004;164:2024-30.

57. Miller PD, Schwartz EN, Chen P, Misurski DA, Krege JH. Teriparatide in postmenopausal women with osteoporosis and mild or moderate renal impairment. Osteoporos Int. 2007;18:59-68.

58. Ishani A, BlackwellT, Jamal SA, Cummings SR, Ensrud KE. The effect of raloxifene treatment in postmenopausal women with CKD. J Am Soc Nephrol. 2008;19:1430-8.

59. Morello KC, Wurz GT, DeGregorio MW. Pharmacokinetics of selective oestrogen receptor modulators. Clin Pharmacokinet. 2003;42:361-72.

60. Barret-Connor EL, Mosca L, Collins P, Geiger MJ, Grady D, Kornitzer $\mathrm{M}$, et al. Effects of raloxifene on cardiovascular events and breast cancer in postmenopausal women. $\mathrm{N}$ Engl $\mathrm{J}$ Med. 2006;355:125-37.

61. Adami S, Palacios S, Rizzoli R, Levine AB, Sutradhar S, Chines AA. The efficacy and safety of bazedoxifene in postmenopausal women by baseline kidney function status. Climateric. 2014 Jun;17(3):273-84.

62. Chesnut $\mathrm{CH}$ 3rd, Silverman S, Andriano K, Genant H, Gimona A, Harris $S$, et al. A randomized trial of nasal spray salmon calcitonin in postmenopausal women with established osteoporosis: the prevent recurrence of osteoporotic fractures study. Am J Med. 2000;109:267-76.

63. Silverman SL, Azria M. The analgesic role of calcitonin following osteoporotic fracture. Osteoporos Int. 2002;13:858-67. 